\title{
PENGARUH BENTUK LAMBUNG KAPAL TERHADAP POLA ALIRAN DAN POWERING PADA KAPAL PERAIRAN SUNGAI DAN LAUT
}

\author{
Sahlan ${ }^{1)}$, Baharuddin $\mathrm{Ali}^{1)}$, Wibowo $\mathrm{HN}^{1)}$, A. Bisri ${ }^{1)}$, Berlian A. ${ }^{2)}$ \\ ${ }^{1}$ Unit Pelaksana Teknis Balai Pengkajian dan Penelitian Hidrodinamika \\ Badan Pengkajian dan Penerapan Teknologi \\ Jl. Hidrodinamika BPPT, Kompleks ITS Sukolilo, Surabaya 60112 \\ Telepon (031) 5948060 \\ e-mail: Sahlan1203@yahoo.com \\ 2 Jurusan Teknik Perkapalan, UNDIP - Semarang
}

\begin{abstract}
Abstrak
Bentuk lambung haluan kapal yang tepat sangat berpengaruh pada perbaikan pola aliran air maupun penurunan tahanan gelombang yang ditimbulkan badan kapal saat beroperasi. Pada tulisan ini dilakukan kajian tentang pengaruh bentuk lambung haluan kapal yang diwakili oleh Model-A dan Model-B terhadap pola aliran, tahanan dan daya poros pada kapal yang merupakan salah satu jenis kapal perairan sungai-laut. Pada Model-B dilakukan modifikasi bentuk haluan dari Model-A. Dari hasil simulasi didapatkan bahwa peningkatan daya poros sebesar 12\% saat kecepatan 14.5 knot pada Model-B atau keuntungan 3\% dari penambahan displaceament $15 \%$ pada Model-B dari bentuk asli Model-A dengan operasional optimum kapal adalah pada kecepatan antara 12 dan 15 knots.
\end{abstract}

Kata kunci : tahanan kapal, bentuk lambung, perairan sungai dan laut, spray

\section{PENDAHULUAN}

Dalam merencanakan sebuah kapal, tahap awal dalam proses teknis kapal adalah menentukan ukuran dan parameter bentuk kapal. Namun besarnya ukuran panjang, lebar, sarat air dan koefisien bentuk yang sudah ditentukan tidak semua kemungkinan akan membawa pengaruh baik, salah satu faktor penting yang terpengaruh dari perubahan ini adalah tahanan kapal atau resistance force. Daya tahanan kapal berhubungan dengan daya mesin yang dibutuhkan suatu kapal untuk mencapai kecepatan yang diinginkan. Sehingga prediksi tahanan kapal sangatlah penting untuk dilakukan sebelum kapal tersebut dibangun.

Pada tulisan ini akan dilakukan analisis terhadap perubahan bentuk haluan atau bow sebuah kapal perairan dangkal hasil kegiatan riset sinas Sahlan et.al [11], [12], yang mana kapal ini sebagai alat transportasi sungai dan laut untuk angkutan barang dan penumpang antar kepulauan. Analisis dilakukan dengan pengujian resistance dengan model test di kolam uji Laboratorium Hidrodinamika Indonesia - BPPT serta sedikit pemaparan hasil prediksi awal secara numerik tahanan kapal. Serta prediksi daya poros kapal.

\section{UJI MODEL}

Pengujian resistance test dilakukan dengan menghubungkan model pada lengan penarik yang terhubung ke alat ukur gaya, kemudian model ditarik oleh carriage. Dari gaya yang terekam itu akan memberikan informasi gaya tahanan badan kapal akibat gesekan lambung kapal dengan air. Gaya tahanan tersebut akan menggambarkan gaya yang dibutuhkan kapal untuk mencapai kecepatan tertentu, hal ini berkaitan dalam penentuan tenaga penggerak kapal nantinya. Selain itu melalui uji kolam ini, akan diketahui secara visual pola aliran disekitar badan kapal saat kapal melaju dalam berbagai variasi kecepatan.

Ukuran utama kapal masing-masing Model-A dan Model-B disajikan sebagaimana berikut :

Tabel 1. Ukuran model

\begin{tabular}{|c|c|c|}
\hline \multirow{2}{*}{$\frac{\text { Simbol }}{\text { Unit }}$} & \multicolumn{2}{|c|}{ Dimensi } \\
\hline & Model-A & Model-B \\
\hline Lpp (m) & 35.70 & 35.70 \\
\hline $\mathrm{B} \quad(\mathrm{m})$ & 7.50 & 7.50 \\
\hline
\end{tabular}




\begin{tabular}{|c|c|c|}
\hline $\mathrm{D} \quad(\mathrm{m})$ & 2.50 & 3.00 \\
\hline (m) & 1.50 & 1.50 \\
\hline (ton) & 220.40 & 254.20 \\
\hline Skala & 9.51 & 9.17 \\
\hline
\end{tabular}

Untuk mengetahui gambaran daya tahanan kapal pada masing-masing model dilakukan resistance test dengan memvariasikan kecepatan kapal sesungguhnya antara $\mathrm{Vs}=6 \sim 20$ knot dalam skala model.

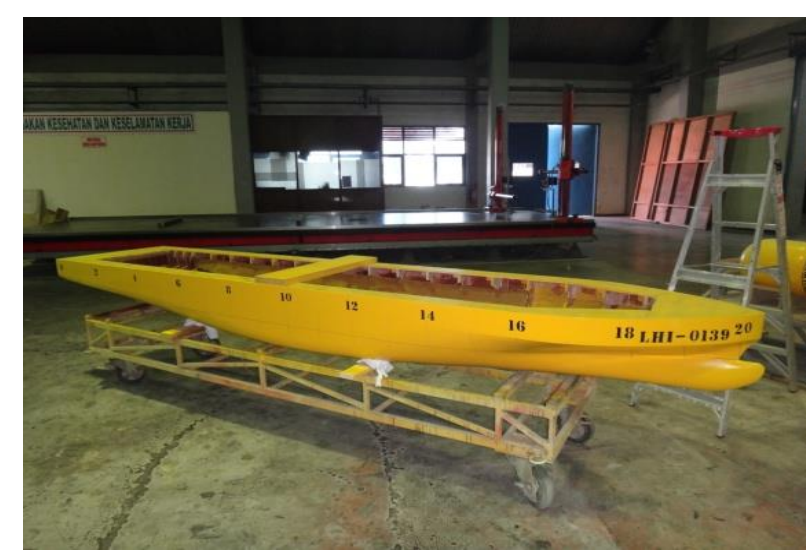

Gambar 1. Model-A

Pada pengujian ini digunakan dua buah model kapal masing-masing Model-A dan Model-B, yang secara dimensi dan bentuk lambung sama namun berbeda desain pada bagian bow atau haluannya, lihat Gambar 1 dan Gambar 2. Pada Model-B terjadi perubahan bentuk haluan dari Model-A yang dimaksudkan untuk memperbaiki pola aliran air maupun diharapkan dapat menurunkan tahanan gelombang yang ditimbulkan badan kapal saat beroperasi.

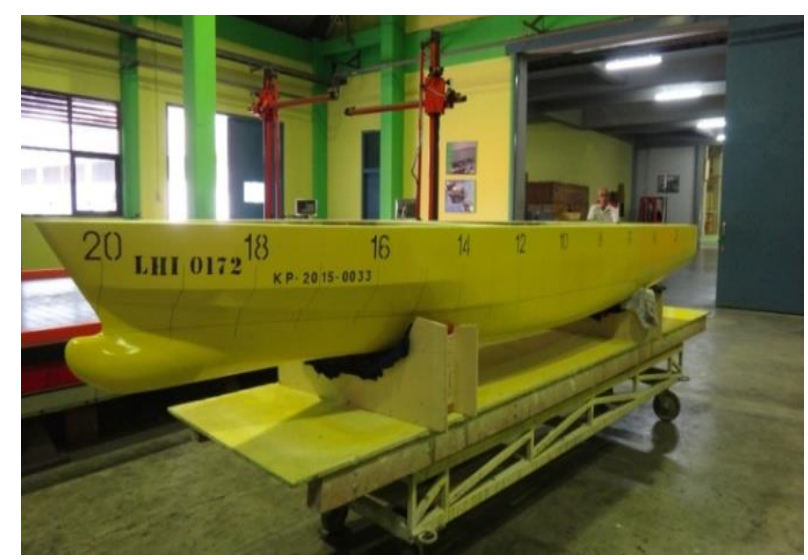

Gambar 2. Model-B

\section{ANALISA DAN DISKUSI 3.1 Pola Aliran Bagian Haluan}

Adanya perubahan bentuk haluan memberikan pengaruh siknifikan terhadap pola aliran yang terjadi pada bagian depan kapal. Pada kecepatan kapal 15 knots terlihat aliran pada bagian depan Model-A spray yang sangat besar ke arah atas dan samping, lihat Gambar 3, hal ini berbeda dengan Model-B pada kecepatan yang sama spray terjadi lebih kecil, merendah dekat permukaan air, lihat Gambar 4. Dan fenomena spray atau wave yang ditimbulkan badan kapal Model-A akan semakin membesar pada kecepatan yang lebih tinggi, lihat Gambar 5. Sedangkan pada Model-B pada kecepatan 17 knots terjadi peningkatan spray namun tidak siknifikan seperti halnya pada Model-A, lihat Gambar 6.

Fenomena spray pada kapal berpengaruh pada operasional kapal maupun pada lingkungan sekitar saat berlayar. Adanya spray yang berlebihan akan meningkatkan wave making resistance akibat spray menghantam badan kapal, sehingga akan menahan laju kapal. Dengan kata lain semakin banyak spray menghantam lambung kapal maka tenaga mesin yang dibutuhkan akan semakin besar untuk mencapai kecepatan kapal yang diinginkan. Selain itu, pola desain haluan kapal selain akan berpengaruh pada timbulnya spray juga timbulnya aliran ke samping badan kapal atau wash.

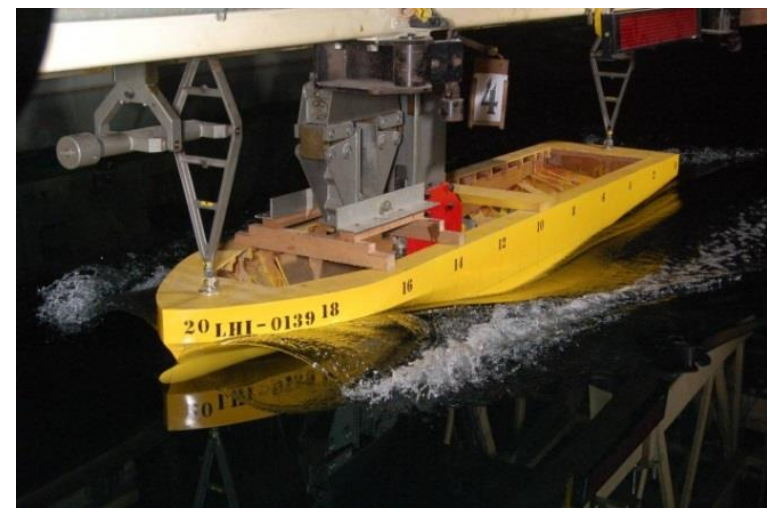

Gambar 3. Model-A, pada kecepatan 15 knots 


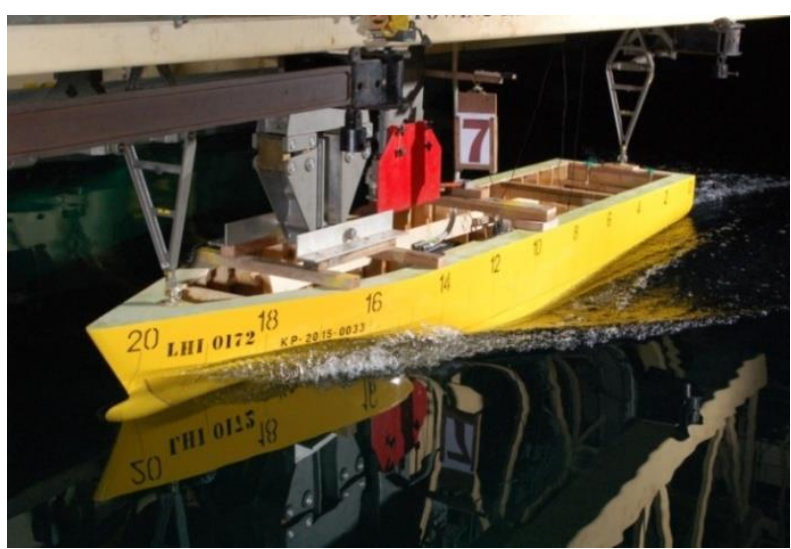

Gambar 4. Model-B, pada kecepatan 15 knots

Timbulnya wash yang berlebihan akan mengganggu pada kapal-kapal yang berada disekitarnya. Pada kapal perairan sungai dan laut ini timbulnya wash yang besar saat beroperasi di sungai akan menimbulkan masalah pada kapalkapal sungai di sekitarnya saat kapal ini melintas, kapal-kapal disekitarnya akan mengalami gerakan tidak beraturan akibat gelombang air sungai membesar akibat wash yang di timbul dari kapal, selain itu wash yang besar akan merusak pinggiran sungai dan menyebabkan erosi akibat semburan wash yang besar. Sehingga pendesainan badan kapal yang lebih baik sangat dibutuhkan untuk dapat mengurangi spray sedemikian rupa yang menghantam badan kapal dan menghasilkan low wash di sekitar kapal.

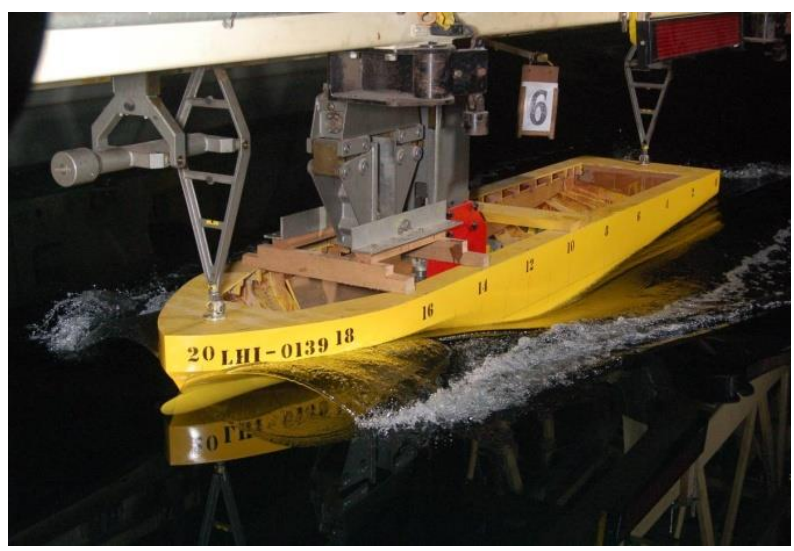

Gambar 5. Model-A, pada kecepatan 17 knots

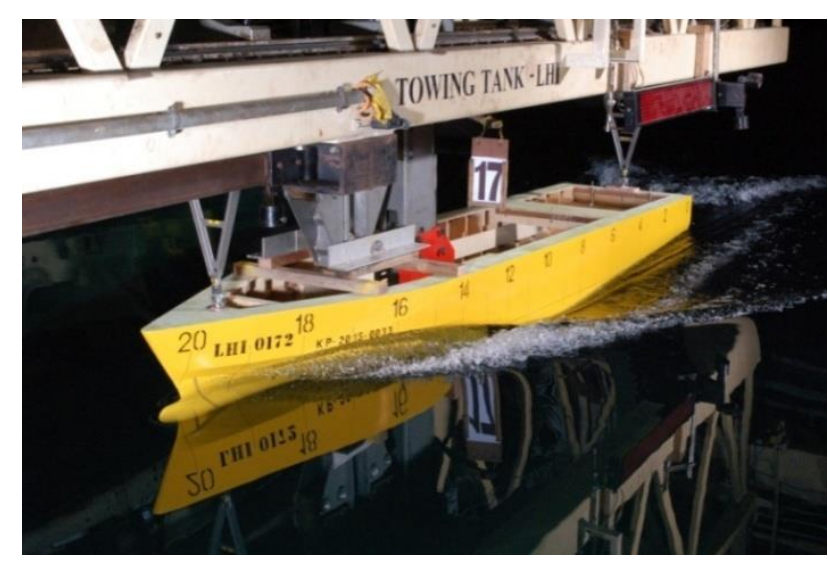

Gambar 6. Model-B, pada kecepatan 17 knots

\subsection{Tahanan Kapal}

Sebelum dilakukan pengujian model, dilakukan simulasi prediksi numerik terhadap gaya resistance kapal. Prediksi dilakukan dengan beberapa metode yaitu; Holtrop, Compton, dan Savitsky. Prediksi gaya tahanan kapal atau gaya resistance disajikan pada Gambar 7. Hasil prediksi masing-masing metode disajikan dengan tanda $\circ=$ metode Holtrop, $\Delta=$ metode Compton, dan $\diamond=$ metode Savitsky. Dari ketiga metode menunjukkan hasil prediksi resistance yang hampir mendekati untuk semua metode. Dari hal tersebut, untuk mendapatkan pendekatan gaya resistance kapal dilakukan interpolasi dari ketiga metode tersebut.

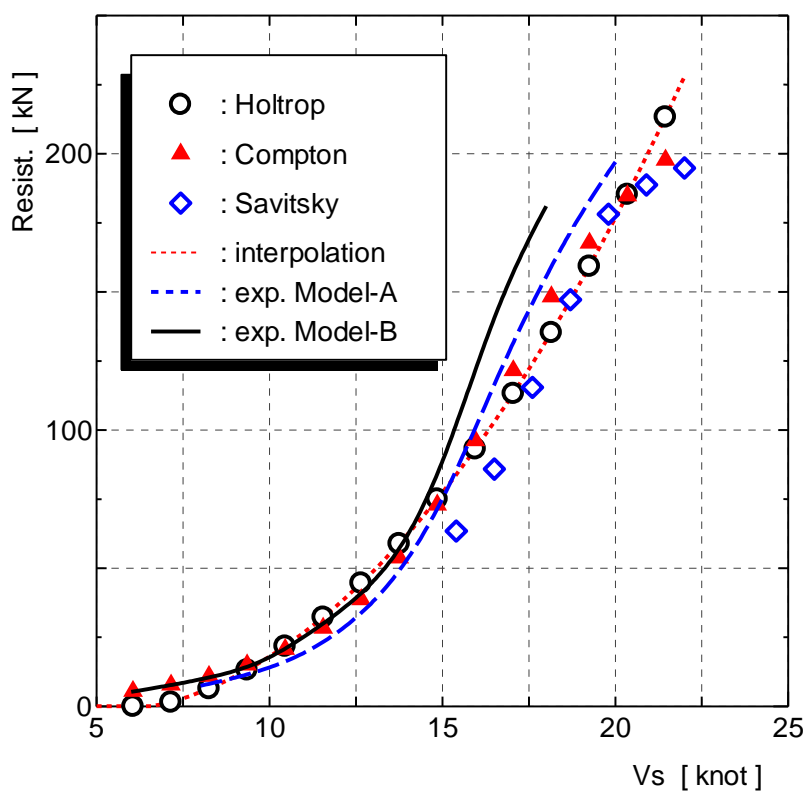


Gambar 7. Perbandingan beberapa metode prediksi tahanan kapal

Dibandingkan dengan hasil uji model pada kapal Model-A dan B, diketahui bahwa hasil prediksi numerik memberikan hasil yang mendekati untuk kecepatan dibawah 14 knots, di atas kecepatan tersebut perbedaan terjadi dan berubah mengikuti pola tahanan kapal dengan perbedaan sekitar $14 \%$ dengan hasil uji Model-A dan 33\% dengan hasil uji Model-B. Dari hasil prediksi ini dapat digunakan sebagai acuan awal dalam prediksi tahanan kapal, namun dari hasil uji model terlihat perlunya penambahan nilai tahanan kapal pada kecepatan tertentu.

Dari hasil uji model tahanan kapal pada ModelA dan Model-B didapatkan hasil sebagaimana disajikan pada Gambar 8. Pola tahanan kapal dalam berbagai variasi kecepatan terlihat seirama antara kedua model. Pada Model-B terlihat sedikit lebih besar 13\% dibandingkan Model-A pada asumsi rencana kecepatan dinas 17 knots.

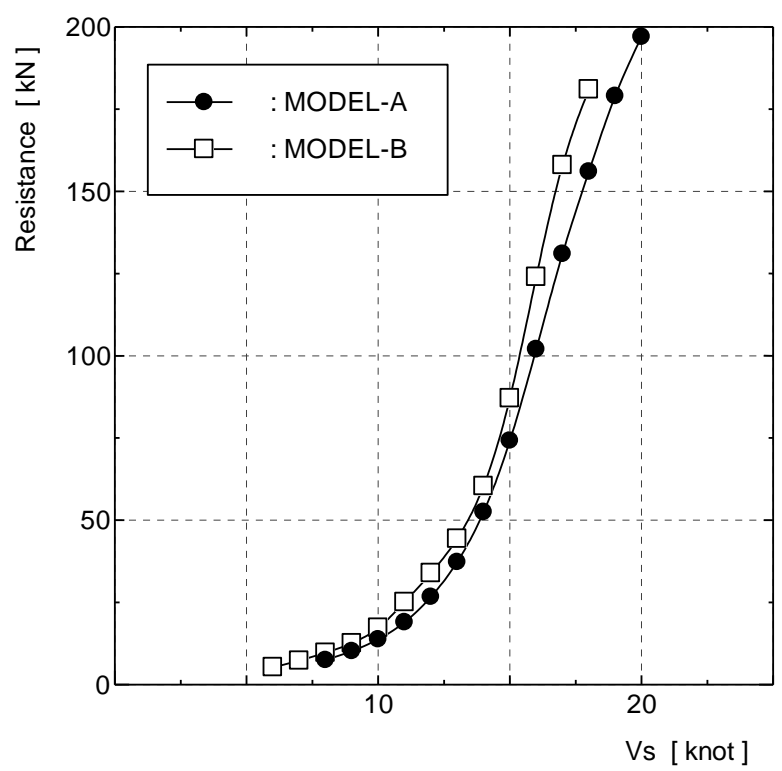

Gambar 8. Perbandingan hasil uji tahanan kapal pada Model-A dan Model B

Pada pengamatan pola aliran, Model-B terlihat lebih bagus dengan adanya perubahan desain haluan, namun hal ini tidak diikuti pada perbaikan dengan penurunan tahanan kapal. Kemungkinan hal ini terjadi akibat perubahan bentuk lambung tersebut mengubah displacement kapal $\Delta$, lihat Tabel 1 tentang ukuran utama kapal. Pada Model-B, perubahan desain haluan mengakibatkan penambahan displcement sekitar 15\%, sehingga kapal lebih berat, maka untuk mencapai kecepatan yang sama dengan Model-A maka dibutuhkan penambahan gaya. Hal ini menjadi suatu hal penting dalam suatu desainer untuk memperhatikan berbagai aspek perubahan desain lambung terkait kinerja kapal yang akan dibuat, perubahan aliran air yang lebih baik pada kapal tidak serta merta mengurangi tahanan kapal manakala displacement kapal bertambah. Namun dari modifikasi desain lambung ini telah memberikan effeisiensi sebesar $2 \%$, hal ini dapat dilihat dengan adannya penambahan displacement $15 \%$ namun penambahan tahanan sebesar $13 \%$.

\subsection{Powering Kapal}

Setelah dilakukan prediksi tahanan kapal maka perlu diprediksi kebutuhan daya mesin atau prediksi powering. Effective power, PE kapal diperoleh dengan mengalikan nilai tahanan dan kecepatan kapal, dimana hasil PE untuk ModelA dan B ditampilkan pada Gambar 9. Pada rencana kecepatan 17 knots PE Model-A sebesar 1745 kW sedangkan Model-B 1908 kW. Karena pola besaran PE sama dengan tahanan kapal maka perbedaan besaran PE antara Model-A dan $B$ adalah sama dengan tahanan kapal.

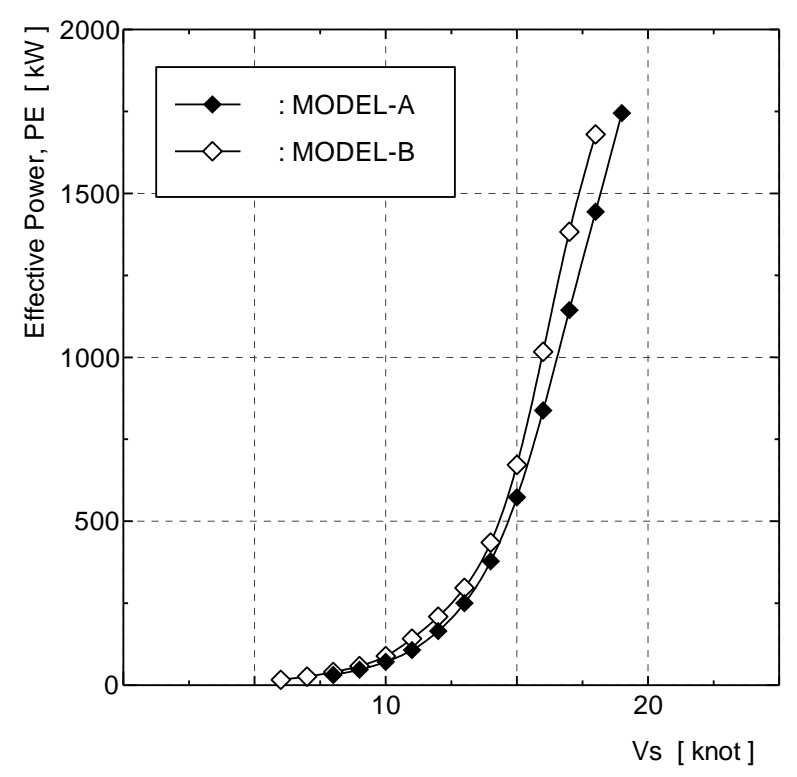

Gambar 9. Perbandingan power effective kapal pada Model-A dan Model B

Dari hasil uji model tersebut kemudian dilakukan prediksi daya yang bekerja pada poros kapal atau shaft power, PS. Prediksi dilakukan dengan menggunakan software DESP yang 
dikembangkan oleh MARIN. Dengan asumsi besaran propulsive coefficient 0.469 maka didapatkan PS untuk Model-A dan B sebagaimana ditampilkan pada Gambar 10. Dari hasil prediksi PS diketahui bahwa terjadi kenaikan kebutuhan daya mesin dalam hal ini PS yang siknifikan pada penambahan kecepatan kapal di atas 14 knots, hal ini berbeda dengan pemakaian daya mesin pada kecepatan kapal antara 12 dan 15 knot dimana kenaikan PS tidak terlihat siknifikan, lihat Gambar 10. Dari hasil prediksi power ini menunjukkan bahwa kapal perairan sungai dan laut ini optimum dioperasikan pada kecepatan antara 12 dan 15 knots.

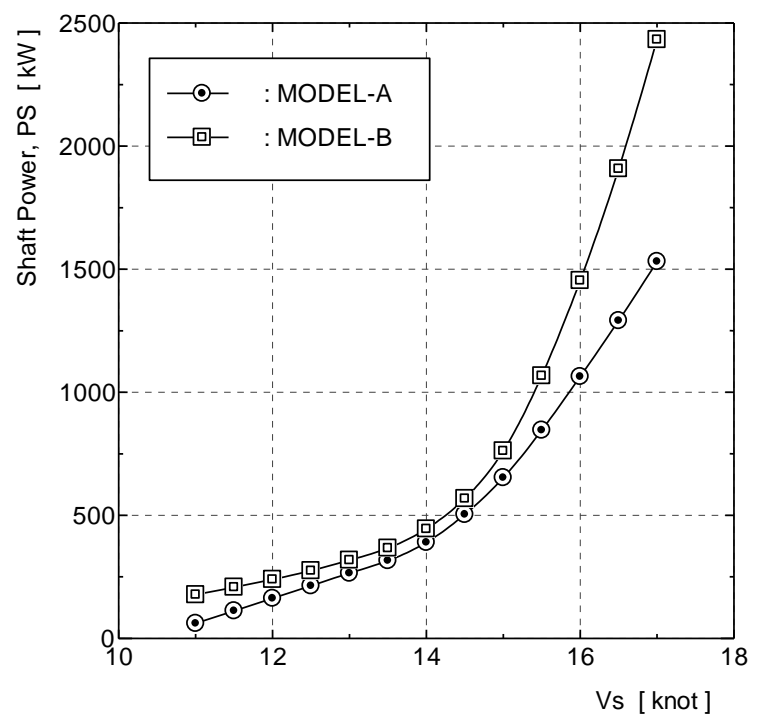

Gambar 10. Perbandingan hasil prediksi shaft power kapal pada Model-A dan Model B

Hasil modifikasi haluan kapal pada Model-B akan memberikan perbaikan kinerja power apabila dioperasikan pada kecepatan 14.5 knot dimana shaft power $568 \mathrm{~kW}$, sedangkan ModelA $504 \mathrm{~kW}$. atau dengan kata lain adanya peningkatan PS pada Model-B sebesar 12\% hal ini masih memberikan keuntungan 3\%, mengingat adanya penambahan $15 \%$ dispalecement dari Model-A.

\section{KESIMPULAN}

Dari hasil pengujian tahanan kapal pada ModelA dan Model-B dapat disimpulkan sebagai berikut :

- Pengurangan spray dan wash akibat saat kapal beroperasi dapat diperbaiki dengan melakukan desain ulang bentuk haluan kapal.
- Model-B memiliki pola aliran spray dan wash yang lebih baik dari Model-A.

- Tahanan kapal Model-B yang lebih tinggi dibanding Model A sekitar $13 \%$, karena ada penambahan displacement sebesar $15 \%$ tidak menjadi masalah karena kapal ini, digunakan dalam operasionalnya untuk angkutan barang dan penumpang jadi dari segi bisnis tetap diuntungkan.

- Dalam perubahan desain perlu memperhatikan aspek teknis dan operasional kapal yang disyaratkan pada spesifikasi kapal yang diinginkan.

- Dari hasil simulasi didapatkan bahwa peningkatan daya poros sebesar $12 \%$ saat kecepatan 14.5 knot pada Model-B atau keuntungan $3 \%$ dari penambahan displaceament $15 \%$ pada Model-B dari bentuk asli Model-A dengan operasional optimum kapal adalah pada kecepatan antara 12 dan 15 knots.

\section{DAFTAR PUSTAKA}

[1] ITTC, Recommended Procedures and Guidelines, Testing and Extrapolation Methodsin Resistance Towing Tank Tests, ITTC 7,5-02-02-02, 2002.

[2] Journee, JMJ. and Pinkster, J, Introduction in Ship Hydromechanics, Lecture Notes, Delf University of Technology, Netherlands, 2002.

[3] Lewis, E.V., Principles of Naval Architecture, Vol. III:Motions in Waves and Controllabity, The Society of Naval architects and Marine Engineers, USA, 1989.

[4] Molland, A.F., A Guide to Ship Design, Construction and Operation, The Maritime Engineering Reference Book, ButterworthHeinemann, Elsevier, 2008.

[5] Molland, A.F., Turnock, S.R., dan Hudson, D.A., Ship Resistance and Propulsion: Practical Estimation of Ship Propulsive Power, Cambridge University Press, New York, USA, 2011.

[6] Sahlan, A. Syafiul M, Kajian Desain Kapal Ferry Cepat Untuk Sarana Transportasi Sebagai Bis Air Untuk Daerah Sungai Musi Hingga Pulau Bangka, diterbitkan pada Proceding Seminar FTK ITS Nopember 2011, sebagai penulis kedua.

[7] Sahlan, Wibowo HN, Kajian Disain Kapal Cepat Berbahan Aluminium Sebagai Sarana 
Transportasi Sungai dan Laut Yang Aman, Nyaman dan Ramah Lingkungan, Kegiatan Insentif SINas KRT 2012, pada Seminar Insentif Ristek di Bandung Techno Park Nopember 2012, sebagai penulis pertama.

[8] Sahlan, dkk, Rekayasa Garis Lambung (Hull Lines) Kapal Untuk Transportasi Sungai dan Laut Yang Handal, Aman dan Nyaman Sebagai Angkutan Penumpang/Barang. Kegiatan Insentif SINas KRT 2013, pada Seminar Insentif Ristek di Jakarta 7-8 Nopember 2013, sebagai penulis pertama.

[9] Samudro dkk, Laporan Akhir "Kegiatan Kajian dan Analisa Teknis Hidrodinamika Untuk Keselamatan Operasional Kapal Cepat Angkut Penumpang/Barang (Program Insentif Terapan KRT tahun 2008-2010).

[10] Sahlan, dkk, Laporan Akhir "Kegiatan Rekayasa Kapal Aluminium Untuk Transportasi Sungai dan Laut (Program Insentif SINas KRT 2012-2013).

[11] Sahlan, dkk, Laporan Akhir "Kegiatan Inovasi Komponen Sistem Penggerak Kapal Perairan Dangkal Sungai dan Laut Program Insentif SINas Kemenristekdikti 2015.

[12] Sahlan, dkk, Pengaruh Bentuk Lambung Kapal Terhadap Pola Aliran dan Tahanan Pada Kapal Perairan Dangkal (Sungai dan Laut), paper presentasi seminar insentif sinas Kemenristekdikti 2015 di Hotel Harris Bandung pada 3-4 Desember 2015. 